Nunt. Antiquus, Belo Horizonte, v. 14, n. 1, p. 111-132, 2018

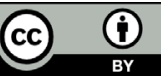

\title{
Vestigia de Ovídio em três biografias da obra De mulieribus claris de Giovanni Boccaccio
}

\author{
Ovidian Vestigia in Three Biographies \\ of Giovanni Boccaccio's De mulieribus claris
}

\author{
Talita Janine Juliani \\ Universidade Federal de Lavras, Lavras, Minas Gerais / Brasil \\ talitajanine@gmail.com
}

Resumo: Em seu catálogo Sobre as mulheres famosas (De mulieribus claris), escrito entre 1361-1362, Giovanni Boccaccio explora o universo mítico greco-romano, retratando a vida de figuras femininas notáveis (clarae) da Antiguidade. Estudos anteriores sobre o De mulieribus claris tendem a ser marcados por um viés dicotômico, que oscila entre apontar um caráter moralista (cristão) ou "meramente" literário nas biografias. Eruditas "pesquisas de fontes" (Quellenforschungen) - as quais são normalmente associadas à segunda perspectiva - destacam, entre outras fontes clássicas, a obra do poeta Ovídio (43 a.C.-17 d.C.). O objetivo central a que se dedica este artigo é investigar como a poesia do autor romano é aludida em De mulieribus claris, e explorar efeitos de sentido de tal presença no catálogo em estudo. Referências ao texto de Ovídio serão apreciadas, valendo-se de preceitos de teoria Intertextual aplicada às Letras Clássicas, em passagens de três biografias, a saber, Tisbe (XIII), Medeia (XVII) e Safo (XLVII). A observação da relação entre os textos dos autores antigo e moderno nos fornece indícios de como se dá o processo de ressignificação do material da Antiguidade na obra boccacciana, passando, de fato, tanto pela reinterpretação de elementos mitológicos no âmbito de uma perspectiva moral cristã, quanto por movimentos de referenciação que filiariam Boccaccio aos grandes autores da Antiguidade.

Palavras-chave: Boccaccio; Ovídio; intertextualidade; personagens femininos.

Abstract: In his catalogue On famous women (De mulieribus claris), written between 1361 and 1362, Giovanni Boccaccio explores the mythical Greco-Roman universe, portraying the life of some of its notable (clarae) female figures. Previous research on De mulieribus claris tends to be marked by a dichotomal trend, namely: pointing 
out in the biographies either a moralist (Christian) character or a "merely" literary one. Erudite "researches on sources" (Quellenforschungen) on the catalogue - which are usually associated to the second perspective - highlight, among other classical sources, the presence of the work of Ovid (43 B.C.-17 A.D.). The main objective of this article is to investigate how the poetry of the Roman author is alluded to in $D e$ mulieribus Claris, and to explore the dynamic effects of that presence in this catalogue. Here, references to Ovid's text will be particularly appreciated - using elements of Intertextual theory applied to classical Letters - in some excerpts of three biographies of the De mulieribus, namely Thisbe (XIII), Medea (XVII) and Sappho (XLVII). The observation of the relation between ancient and modern authors' texts gives us signs of the process of resignification of classical material in the Boccaccian work, in which the mythological element is reinterpreted within a Christian moral perspective, and is also part of a reference system that links Boccaccio to the great authors of Antiquity.

Key-words: Boccaccio; Ovid; Intertextuality; female characters.

\section{De Mulieribus: entre edificação moral e divulgação cultural ${ }^{1}$}

Ao tratar do processo imitativo que Giovanni Boccaccio (13131375) realiza em De mulieribus claris (1361-1362), buscamos observar em que extensão se pode identificar, de que modo se dá e que efeitos de sentido traz a presença da obra do poeta romano Públio Ovídio Nasão (Publius Ouidius Naso, 43 a.C.-17 d.C.) nesse catálogo biográfico produzido no trecento italiano. Um exame mais atento do modo como o texto ovidiano é referido em De mulieribus claris se revela profícuo em vários planos: como pretendemos apontar neste artigo, esse tipo de atenção mostra-se importante tanto para a compreensão do sentido de várias passagens do catálogo biográfico em foco, quanto, de modo mais geral, para a percepção de relações de Boccaccio com a cultura não cristã antiga.

Percebe-se, ainda, que a escolha dessa perspectiva de investigação do De mulieribus acaba por trazer implicações também quanto a questões mais gerais, tradicionalmente colocadas nos estudos boccaccianos. Dentre elas, destaca-se, por exemplo, a discussão sobre os gêneros textuais

\footnotetext{
${ }^{1}$ Neste artigo tratamos de alguns aspectos que, posteriormente, foram trabalhados de forma mais abrangente e sob outras perspectivas em meu mestrado (JULIANI, 2011) e em meu doutorado (JULIANI, 2016).
} 
observáveis no texto de Boccaccio (BRANCA, 1976), bem como a presença de obras de outros gêneros (antigas, medievais, coevas ao autor, ou mesmo de sua própria autoria) em que o autor teria haurido para compor De mulieribus (HORTIS, 1879; TORRETA, 1902; ZACCARIA, 1967; MCLEOD, 1991). O último ponto, que também envolve a presença de elementos religiosos, morais, retóricos e poéticos (sejam eles antigos ou medievais, cf. CERBO, 2001; KOLSKY, 2003), tem efeitos sobre a consideração da debatida postura moralista do certaldense (CERBO, 2001).

Considerando essa abordagem que vê no texto de Boccaccio a mera releitura de temas antigos sob o ponto de vista da cristandade, Zaccaria (1967, p. 5-6) nos diz, em sua introdução à tradução italiana, que convites à virtude e aversão ao vício não seriam, na verdade, o mais importante em De mulieribus: "O propósito da edificação é inferior àquele da divulgação cultural" (ZACCARIA, 1967, p. 6). ${ }^{2}$ Tais palavras do estudioso expressam algo muitas vezes pressuposto nas pesquisas sobre a obra: uma dicotomia entre edificação moral (i.e. espiritual, cristã) e a apreciação do elemento da cultura (que tende a ser vista como pagã). A perspectiva que defendemos pretende rever, em excertos do texto boccacciano, a pertinência de uma percepção tão dicotômica.

Em primeiro lugar, ao privilegiar as relações entre os textos de Boccaccio e de um autor antigo pagão, nosso intuito não seria negar a influência de, por exemplo, autores como Jerônimo e Paulo (BROWN, 2001, p. xvi), ou ainda de outros pais da Igreja, sobre o De mulieribus. Na esteira de estudiosos como Garin (1994), reconhecemos que, no período em que as obras do certaldense foram produzidas, toda a erudição humana voltava-se ao ensinamento e à formação do homem virtuoso, o que à época implicava que se desse necessariamente por meio da afirmação dos valores morais cristãos. Observar como categorias antigas (das obras imitadas) se conjugam com estes valores coevos a Boccaccio nos parece, então, um critério pertinente para a apreciação estética de suas produções literárias e culturais.

Paralelos entre De mulieribus claris e obras e autores da Antiguidade grego-romana também têm sido muito destacados

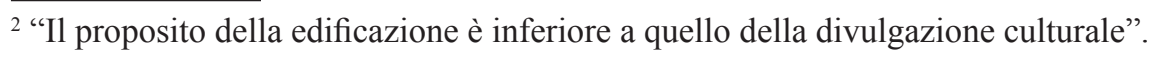


na bibliografia secundária interessada em "pesquisa de fontes" (Quellenforschungen), principalmente nas abundantes notas à tradução de Zaccaria do catálogo de Boccaccio. ${ }^{3}$ No entanto, efeitos de sentido de tal imitatio propriamente ditos parecem ser valorizados apenas mais recentemente, como é o caso de abordagens baseadas na intertextualidade. ${ }^{4}$ Com inspiração neste tipo de abordagem, e à luz de textos ovidianos, apresentaremos algumas leituras de passagens de algumas biografias em De mulieribus, a saber a biografia de Medeia (XVII), de Tisbe (XIII) e de Safo (XLVII).

\section{O olhar de Medeia}

Já se notou no mito de Medeia narrado na biografia de número XVII em De mulieribus paralelos com as versões que Ovídio apresenta tanto no poema épico Metamorphoses (VII, v. 1-452, datada de 2 d.C.8 d.C.?) quanto na elegia epistolar da obra Heroides (XII, datada de 20-16 a.C.). ${ }^{5}$ Semelhanças vão desde os episódios narrados nos textos, até elementos lexicais e imagéticos. Entre as referidas semelhanças, constatamos na personagem Medeia do De mulieribus claris um aspecto marcante das versões ovidianas do mito antigo. Trata-se das constantes referências aos perigos do olhar. ${ }^{6}$

${ }^{3} \mathrm{Cf}$. A edição do texto boccacciano feita por Branca (1967).

${ }^{4}$ Cf. sobre intertextualidade em De mulieribus: Cerbo (1984) e Cavallari (2006), referente ao Decameron. Ver ainda Conte (1986) e Barchiesi (1984) para referências bibliográficas relacionadas à teoria intertextual aplicada a textos da literatura grecoromana antiga. Sobre noções de imitação em diferentes metodologias empregadas em Letras Clássicas, cf. Cardoso (2009).

5 "Per Medea, in generale, cfr. Ovídio, Metamorphoseon, VII i ss.; Epistulae, XII" (ZACCARIA, 1967, p. 497, nota 1).

${ }^{6} \mathrm{Cf}$. por exemplo: "Que homem sensato chegaria a pensar que, de uma única mirada de seus olhos, pudesse derivar o extermínio de um opulentíssimo rei?" (Quis hoc etiam sensatus arbitr<ar>etur homo quod ex uno oculorum intuitu opulentissimi regis exterminium sequeretur?; De mulieribus, XVII, §5); e "Por que temo a morte de alguém em quem apenas agora pus os olhos?" (Cur, quem modo denique vidi,/ Ne pereat, timeo?; Metamorphoses, VII, v. 15-16). As traduções, tanto de Ovídio quanto de Boccaccio são, salvo indicação, nossas. 
A indicação dos olhos como o fator que levou Medeia à ruína se mostra, em Ovídio, quando ela vislumbrou Jasão sob um bosque umbroso, como se vê nas Metamorphoses (VII, v. 86-88): "Ela o avista [spectat] e, afinal, mantém fixos os lumes [lumina fixa] no vulto visto [uiso], e insana, não julga estar vendo [lidere] rosto mortal, nem dele se desvia". ${ }^{7}$ Nas Heroides a ênfase se dá em versos sonoros e sentenciais: "Então eu te vi, então comecei a saber quem eras: isto foi a primeira ruína de minha razão. Te vi e me perdi" " (Heroides, XII, v. 31-33. Ver ainda BESSONE, 1997, p. 104).

Considerando a expressividade do elemento do olhar nas breves passagens de Ovídio referenciadas, podemos ler, agora nos últimos parágrafos da biografia de Medeia em Boccaccio, a seguinte afirmação: "Mas, que eu não deixe passar em silêncio: não se deve conceder aos olhos uma total liberdade" (De mulieribus, XVII, §11). ${ }^{9}$ Além disso, é a esta afirmação que se segue uma longa reflexão (De mulieribus, XVII, §11-14) sobre os perigos morais despertados pelo mau uso dos olhos, excerto cuja tradução transcrevemos aqui, a fim de fundamentar a interpretação que gostaríamos de sugerir:

Mas, que eu não deixe passar em silêncio: não se deve conceder aos olhos uma total liberdade. Isso porque, ao olharmos, reconhecemos os esplendores, incutimos inveja, atraímos tudo quanto é concupiscência; através do olhar, a avareza é provocada, a beleza é louvada, o desalinho e a pobreza são condenados sem merecimento; e porque são juízes não doutos e acreditam somente no que é superficial, muitas vezes antepõem ao sacro o que é ignominioso; às verdades, as coisas

\footnotetext{
${ }^{7}$ Para os textos latinos das obras ovidianas aqui mencionadas, cf. as edições da coleção Belles Lettres, Les amours (1924), Héroides (1965), L'art d'aimer (1965), Les métamorphoses. I-V(1999) e Les métamorphoses. VI-X(2000), conforme constam nas referências bibliográficas ao fim do texto.

${ }^{8}$ Tunc ego te uidi, tunc coepi scire, quid esses; / illa fuit mentis prima ruina meae./ Et uidi et perii.

${ }^{9} \mathrm{Sed}$, ne omiserim, non omnis oculis prestanda licentia est.
} 
falsas, e às alegrias, as angustiantes. E à medida que recomendam o que deveria ser enjeitado e os prazeres efêmeros, corrompem os espíritos não raro por meio de torpíssima desonra. Os olhos, néscios, são capturados, arrastados, arrebatados e retidos por mordazes iscas: pela beleza (mesmo pela desonesta), pelos movimentos lascivos, pela petulância juvenil. E uma vez que são a porta da alma, por eles a libido envia mensagens à mente, através deles o desejo insufla suspiros e incute cegas chamas, por eles o coração deixa escapar lamentações e manifesta seus sentimentos sedutores. Os olhos, se alguém tivesse de fato sensatez, ou seguramente os fecharia, ou os levantaria para o céu, ou ainda os mergulharia na terra. A eles, nenhum caminho entre tais instâncias é porventura seguro; ou, se for necessário deles fazer uso, devem ser coibidos com estrito freio, para que não caiam em lascívia. A natureza designou aos olhos que fossem portas, não para que fossem fechados somente no sono, mas para que barrassem o que é nocivo. Sem dúvida, se a poderosa Medeia os tivesse fechado, ou os dirigido para outra parte quando os ergueu ávida na direção de Jasão, teria permanecido por muito tempo o poder do pai, a vida do irmão e, intacta, a virtude de sua virgindade: todas estas coisas pereceram por causa da impudicícia dos olhos. (De mulieribus, XVII, §11-14. Grifos nossos). ${ }^{10}$

${ }^{10}$ Sed, ne omiserim, non omnis oculis prestanda licentia est. Eis enim spectantibus, splendores cognoscimus, invidiam introducimus, concupiscentias attrahimus omnes; eis agentibus, excitatur avaritia, laudatur formositas, damnatur squalor et paupertas indigne; et cum indocti sint iudices et superficiebus rerum tantummodo credant, sacris ignominiosa, ficta veris et anxia letis persepe preficiunt; et dum abicienda commendant et brevi blandientia tractu, inficiunt nonnunquam animos turpissima labe. Hi nescii a formositate, etiam inhonesta, a lascivis gesticulationibus, a petulantia iuvenili mordacibus uncis capiuntur trahuntur rapiuntur tenenturque; et, cum pectoris ianua sint, per eos menti nuntios mictit libido, per eos cupido inflat suspiria et cecos incendit ignes, per eos emictit cor gemitus et affectus suos ostendit illecebres. Quos, si quis recte saperet, aut clauderet, aut in celum erigeret, aut in terram demergeret. Nullum illis 
Como podemos ver, os olhos, "a porta da alma" (cum pectoris ianua sint; §12), são também "juízes não doutos" (indocti [...] iudices; $\S 11$ ). Por isso, se voltados aos lugares errados, levam à lascívia (lascivis gesticulationibus; §12), à avareza (avaritia; §11), ao que é mal e falso. Segundo podemos inferir da exegese boccacciana ao mito de Medeia, os olhos somente devem fitar o chão ou o céu (aut in celum erigeret, aut in terram demergeret; $§ 13)$.

Tais correspondências parecem sugerir, então, que o leitor do texto latino do De mulieribus, uma vez conhecedor de Ovídio, não deixaria de constatar a presença do autor romano nessa biografia. No entanto, em que essa presença ovidiana, e a comparação com o texto de Ovídio, nos ajuda a reconsiderar as leituras que normalmente se fazem da biografia boccacciana em De mulieribus? Primeiro, ficam mais evidente os contrastes.

Já se apontou que, dentre as inúmeras versões do mito de Medeia, as inquietudes e aporias expostas várias vezes em primeira pessoa pela Medeia de Ovídio nas Metamorphoses e Heroides têm em si uma representação brilhante (cf. por exemplo, Hill, 1992, p. 195). Já a personagem de De mulieribus em um primeiro momento parece não ser construída de modo psicologicamente tão complexo quanto o da personagem ovidiana. Colabora para isso o fato de o narrador a apresentar em terceira pessoa, mais distanciada. A narrativa em primeira pessoa que perpassa o texto em diversos momentos de Metamorphoses, VII e no texto de Heroides, XII colabora para que as questões de conflito - já colocadas nas obras antigas - fiquem mais evidentes.

Embora evidentemente os gêneros historiográficos e biográficos não deixem de fazer uso de discurso direto, é possível pensar que, ao transmitir a história em terceira pessoa, Boccaccio obtenha como efeito, na parte "expositiva", um distanciamento entre leitor e personagem. Dessa forma, concordando com Kolsky (2003), parece que o autor

inter utrumque tutum iter est; quod si omnino peragendum sit, acri sunt cohibendi, ne lasciviant, freno. Apposuit illis natura fores, non ut in somnum clauderentur solum, sed ut obsisterent noxiis. Eos quippe si potens clausisset Medea, aut aliorsum flexisset dum erexit avida in Iasonem, stetisset diutius potentia patris, vita fratris et sue virginitatis decus infractum: que omnia horum impudicitia periere. 
toscano subordina o texto a uma estrutura menos dramática (no sentido etimológico do termo drama, ligado à ação das personagens ${ }^{11}$ ) que a de Ovídio, e, com isso, mais analítica, mais autorizada e moralizante. ${ }^{12}$ Uma moralização em que se reconhece o pensamento cristão é obtida também, no texto boccacciano, por meio da supressão da metamorfose etiológica omissão que faz parte de uma tendência adotada por Boccaccio também em vários outros episódios míticos, caracterizada seja pelo evemerismo ${ }^{13}$ seja pela alegoria. ${ }^{14}$

De todo modo, vemos que em seu retrato de Medeia, Boccaccio confere ao texto de Ovídio um direcionamento que caracteriza moralmente a condução do olhar da mulher biografada. Localizando Medeia entre o vício e a virtude - ou melhor dizendo, no extremo polo da falta de virtude $^{15}$ - essa biografia corrobora esse movimento que já foi apontado por Morse (1996, p. 203-204), e por outros estudiosos quanto a outras passagens de biografias boccaccianas. ${ }^{16}$

Em Boccaccio (cf. XVII, §11-14), a reflexão moralizante que se segue à menção dos perigos do olhar pode ser apontada como aquela que, em comparação com os textos de Ovídio, tem a função mais declarada de educar seus leitores. Em De mulieribus, sobretudo no comentário de Boccaccio ao texto de Medeia (XVII, §11-14), tem-se, pois, um didatismo mais à flor do texto (para não dizer quase dogmático). É verdade que

${ }^{11}$ Cf. VI, 1449b, 21-35 da Poética de Aristóteles.

${ }^{12}$ Cf. Kolsky (2003, p. 37).

${ }^{13}$ Para um breve comentário sobre o evemerismo (uma tendência de interpretação dos mitos na linha da proposta por Evêmero (IV a.C.), na qual os deuses são considerados homens divinizados por sua fama) em Boccaccio, cf. Torreta (1902, p. 272).

${ }^{14}$ Jocelyn (1997), a respeito da Genealogia deorum gentilium, catálogo mitológico do autor certaldense, aponta para uma leitura alegórica dos mitos por parte de Boccaccio. 15 "Medeia, crudelíssimo exemplo da antiga perfídia, era filha de Eeta - ilustríssimo rei dos colcos e cônjuge de Perse - suficientemente bela e, mais que todas, doutíssima em malefícios" (Medea, sevissimum veteris perfidie documentum, Oete, clarissimi regis Colcorum, et Perse coniugis filia fuit: formosa satis et malefitiorum longe doctissima; De mulieribus, XVII, §1).

${ }^{16}$ Cf. Cerbo (2001) referindo-se a De genealogia; e Kolsky (2003, p. 34-35) à Tisbe (XIII) e outras biografias do De Mulieribus (Pocris, XXVIII, por exemplo). 
essa impressão se dá, em parte, porque a percepção de um teor didático ${ }^{17}$ por parte do autor da Antiguidade requer de seu leitor moderno ${ }^{18}$ uma apreensão mais atenta, sobretudo em poemas que brincam tanto com gêneros poéticos diversos.

Em sua obra Trattatello in laude di Dante (1351-1366), também um texto de caráter biográfico, Boccaccio mesmo afirma que a poesia e a teologia ${ }^{19}$ estariam intimamente ligadas. ${ }^{20}$ Isso porque, segundo ali aponta o autor, os poetas seriam responsáveis por moldar a percepção dos leitores cristãos, e colaborariam, com isso, para estabelecer preceitos religiosos. Obviamente, ao buscar determinar o virtuosismo ou a falta dele na construção de sua Medeia, o autor toscano consolida sua visão teológica moral: mas ele o faz usando da poesia ovidiana.

\section{0 ardor de Tisbe}

Talvez uma passagem da biografia de Tisbe $^{21}$ (XIII) em De mulieribus também denuncie a interpretação moralista do Boccaccio autor em relação à retratada. Trata-se, segundo propomos, do trecho em que Boccaccio descreve o momento em que a personagem sai de casa para encontrar Píramo e realizarem sua fuga. Observemos primeiro a versão

${ }^{17}$ Sobre as ambiguidades do didatismo em Ovídio, inclusive nas Metamorfoses, cf. Habinek; Schiesaro (2004). Graf(2002, p. 108) chama a atenção para o que ele chamaria de "Ovid's irreverent playfulness". Cf. também Trevizam (2003).

${ }^{18}$ Fosse aquela a quem Boccaccio dedica sua obra (Andrea Acciauioli), ou ainda a outros coevos do certaldense.

${ }^{19}$ Sobre essa relação entre poesia e teologia ver os livros XIV e XV da De genealogia deorum gentilium (cf. ainda MAZZOTTA 2003, p. 355).

20 "I say that Theology and Poesy may be considered to be almost one and the same thing. I say further that Theology is naught else than a certain Poesy of God" ("Eu digo que teologia e Poesia podem ser consideradas quase uma única e mesma coisa. Eu digo ainda que a Teologia é nada mais que um certo tipo de Poesia de Deus"; BOCCACCIO apud MAZZOTA, 2003, p. 354).

${ }^{21}$ Zaccaria (1967, p. 493, nota 1) nos diz que "[...] Il capitolo è naturalmente tratto, con riprese perfino letterali, dal noto episodio di Ovidio, Metamorphoseon, IV 55 ss. [...]" ("O capítulo é naturalmente desenhado, com retomadas até mesmo literais, a partir do conhecido episódio de Ovídio, nas Metamorfoses, IV 55 ss. [...]”). 
ovidiana em Metamorphoses, IV, em que temos: "Chegado o momento, pela escuridão a hábil Tisbe sai e engana os seus. Com o rosto coberto, chega até o túmulo e se senta sob a árvore determinada. $\mathrm{O}$ amor a fazia audaciosa" (v. 93-96). ${ }^{22}$

Em Ovídio, os termos callidus, fallere e audacia caracterizam Tisbe por meio de um vocabulário que poderia ser associado, por exemplo, àquele utilizado pela comédia nova romana, ${ }^{23}$ e que também se relacionaria ao tom mais leve da linguagem da poesia elegíaca ovidiana. Boccaccio, por sua vez, acrescenta à passagem (no passo correspondente da narrativa) a seguinte sugestão: "Primeiro Tisbe, talvez mais ardente [ardentior forte], enganou os seus" (De mulieribus, XIII, §4). ${ }^{24} \mathrm{De}$ certa forma, o eco da expressão audacem faciebat amor ("O amor a fazia audaciosa"), com que Ovídio justificava a audácia da moça vítima do amor, pode ser observado também no excerto boccacciano. Mas, o emprego do termo ardens ("ardente") com frequente teor erótico em língua latina ${ }^{25}$ pode dar a entender nessa passagem da obra De mulieribus que Tisbe, a biografada, arderia mais em amor, em desejo, do que seu amado, Píramo. Aqui, nossa hipótese é de que, com essa sutil mudança, não escapariam ao leitor boccacciano ecos de um estereótipo de mulher: o da mulher lasciva, já existente na poesia antiga (por exemplo na comédia de Aristófanes), ${ }^{26}$ mas que também é facilmente encontrado em tantos textos mais próximos à era de Boccaccio, da Idade Média (cf. Bloch, 1995; Duby, 1989 e Duby; Perrot, 1990).

${ }^{22}$ Callida per tenebras versato cardine Thisbel egreditur fallitque suos adopertaque vultum/ pervenit ad tumultum dictaque sub arbore sedit./ Audacem faciebat amor.

${ }^{23}$ Para mais sobre as astúcias dos serui callidi, os escravos enganadores, personagens de comédia de Plauto e de Terêncio, cf. Petrone (1983) e Cardoso (2005).

${ }^{24}$ Ardentior forte Tisbes prima suos fefellit [...].

${ }^{25}$ Cf. verbete ardens no Oxford Latin Dictionary, sentido 4: "(of emotions, zeal, etc.) Intense, passionate, ardent, burning” ("(de emoções, zelo, etc.) Intenso, apaixonado, ardente, fogoso"). Note-se o uso do mesmo vocábulo para descrever o modo como Medeia amava Jasão: dilexit ardenter (De mulieribus, XVII, §4).

${ }^{26}$ Sabe-se que estereótipos desse tipo - de que as mulheres teriam mais apego do que os homens ao sexo, por exemplo - já eram topoi antigos (cf., para exemplos em Aristófanes, Cardoso, 2011, p. 9-38). Cf. também Henderson (1990). 
Consideremos, entretanto, que, embora tal termo ardens permita uma tal interpretação judiciosa de Tisbe, e que isso reforce certa percepção dos textos do De mulieribus como que carregados de elementos de fortes, senão incisivos, julgamentos morais, deve-se destacar que nesta biografia o autor parece não se privar de demonstrar também outro valor cristão: a compaixão para com a retratada. Isso porque, segundo Kolsky (2003), precisamente neste capítulo Boccaccio também se expressará de modo mais ameno em relação às "faltas" da personagem, não para diminuir a crença pagã em uma espécie de ironia, mas para demonstrar certa empatia com a personagem. Nas palavras do estudioso, "o escritor medieval cristianiza o episódio a fim de que ele consiga demonstrar simpatia por Tisbe, e não ridicularizar sua fé nos deuses que ela invoca antes de cometer suicídio" (KOLSKY, 2003, p. 34. Tradução nossa). ${ }^{27}$ Vejamos, então, um excerto da biografia XIII em que ficaria clara a demonstração de compaixão pela personagem:

Quem não se compadecerá dos jovens? Quem não concederá ao menos uma só lágrima a tão infeliz fim? O que assim fizer será feito de pedra. Crianças amaram: mas não por isso mereciam um sangrento infortúnio por causa deste infortúnio. $\mathrm{O}$ amor é um erro comum aos que estão na flor da idade, mas não é um crime horrendo aos solteiros, pois seria possível conduzirse ao matrimônio. A odiosa sorte procedeu mal, e talvez os miseráveis pais também o tenham feito. Isso porque os ardores dos jovens devem ser contidos gradualmente, evitando que os lancemos desesperados contra o precipício ao desejarmos tolhê-los com repentino obstáculo. (De mulieribus, XIII, $\S 12,13) .{ }^{28}$

27 "The medieval writer Christianizes the episode so that he is able to show sympathy for Thisbe and not ridicule her faith in the gods upon whom she calls before committing suicide". ${ }^{28}$ Quis non compatietur iuvenibus? Quis tam infelici exitui lacrimulam saltem unam non concedet? Saxeus erit. Amarunt pueri: non enim ob hoc infortunium meruere cruentum. Florentis etatis amor crimen est, nec horrendum solutis crimen; in coniugium ire poterat. Peccavit fors pessima et forsan miseri peccavere parentes. Sensim quippe frenandi 
Dessa forma, embora o que chamamos de "juízos de valor" não esteja ausente no tratamento conferido por Ovídio aos seus mitos, ${ }^{29}$ é bastante plausível pensar que o modo como o autor do século XIV configura os seus juízos em De mulieribus (e, portanto, sua persona enquanto autor) evoca elementos posteriores à chamada tradição clássica greco-romana. Ao que nos parece, é isso que teria feito Boccaccio em Medeia, ao amplificar em forma de "exegese" (CERBO, 2001) a referência ovidiana ao olhar e, em Tisbe, com a breve introdução da qualificação da personagem como ardentior, bem como pela exortação à piedade pelos jovens amantes.

\section{Safo e a persona autoral em De Mulieribus}

A fim de fomentar nossa breve discussão sobre a biografia de $\mathrm{Safo}^{30}$ em De mulieribus, consideremos a interessante perspectiva de Alessandro Barchiesi e Philip Hardie (2010) sobre a construção de uma persona boccacciana em um estudo intertextual realizado entre a mais célebre obra de Boccaccio em vernáculo, o Decameron (1348-1351), e textos do poeta sulmonense, a saber, a Ars amatoria (1 a.C.) e os Remedia Amoris (1 d.C.). No referido estudo, os pesquisadores constatam no texto de Boccaccio diversas alusões à obra amatória ovidiana a fim de demonstrar a construção de um ethos de autoria boccacciana, e, mais propriamente, a construção de elementos de uma "carreira poética"31 (BARCHIESI; HARDIE, 2010, p. 64) aos moldes da de Ovídio. Essa análise, além de sugerir algo que nos servirá de reflexão sobre $D e$

sunt iuvenum impetus, ne, dum repentino obice illis obsistere volumus, desperantes in precipitium inpellamus.

${ }^{29}$ Para citar apenas um exemplo, lembremos como Ovídio considera o juízo acerca da culpa ou inocência do personagem Actéon (Metamorphoses, III, v. 138-252), cf. Cardoso (2005, p. 45-62).

${ }^{30}$ Safo, poetisa grega do século VII a.C., uma figura feminina que no De mulieribus de Boccaccio se afasta de Medeia e Tisbe por se tratar se personagem histórica, embora muito pouco se saiba sobre a autora empírica.

${ }^{31}$ Sobre o desenho de uma vida na literatura, remetemos ao livro a que pertence o referenciado artigo de Barchiese; Hardie (2010): Hardie; Moore (2010). Para a construção de uma imagem autoral na antiguidade, cf. Vasconcellos (2016). 
mulieribus - ou seja, que ao remontar à Antiguidade o autor certaldense nem sempre o faz tendo em vista pregar primordialmente uma moral cristã, ${ }^{32}$ mas visa também referenciar uma tradição poética a fim de, alinhando-se a ela e a seus preceitos, integrá-la -, indica também, em nosso entender, que aspectos da carreira literária que Ovídio constrói para si ao longo de suas obras transparecem também na biografia que Boccaccio apresenta para a poetisa Safo (XLVII) ${ }^{33}$ na obra De mulieribus. Dois aspectos dessa biografia amparam aqui nossa afirmação: um deles é a imagem de autoria da Safo boccacciana e a da ovidiana; outro é a aproximação da poetisa com o mundo divino. Então, investigaremos brevemente os elementos apresentados na referida biografia de Safo em De Mulieribus e na carta XV das Heroides de Ovídio.

Em primeiro lugar, no que tange à caracterização da poetisa, cabe dizer que tanto o texto de Boccaccio quanto a epístola XV das Heroides apresentam Safo como sendo uma autora elegíaca. ${ }^{34} \mathrm{E}$ ambos usam da

32 "We have registered the Ovidian invocations in the sequential order they have in the text of the Decameron because our interest is in the dynamic effect that those intertextual contacts create, both in Boccaccio's text, and as a rereading of Ovid's career and its unforgettable consecutio temporum. In the unruly appropriative culture of the Middle Ages, the very fact that the Ovidian texts are being alluded to in their unmistakable proper autographical order (Ars amatória - Remedia - Tristia) should give one pause" ("Temos registrado as invocações ovidianas na ordem sequencial em que aparecem no texto de Decameron porque nosso interesse está no efeito dinâmico que esses contatos intertextuais criam, tanto no texto de Boccaccio, quanto em uma releitura da carreira de Ovídio e sua inesquecível consecutio temporum. Na desordenada cultura apropriativa da Idade Média, o próprio fato de que textos ovidianos estão sendo aludidos em sua própria e inconfundível ordem autógrafa (Ars amatoria - Remedia - Tristia) deveria dar uma pausa"; BARCHIESI; HARDIE, 2010, p. 87).

${ }^{33}$ Cf. Zaccaria (1967, p. 517, nota 1).

${ }^{34} \mathrm{Knox}$ nos lembra que, apesar de Safo (séc. VI ou VII a.C.) ter realmente escrito poesia elegíaca grega, parecia incomum retratá-la como representante de tal gênero. Vejamos as palavras do próprio estudioso: "The biographical tradition mentions that she also wrote elegiac poetry (Suda s.v. $\Sigma \alpha \pi \varphi \omega ́$; P. Oxy. 1800, fr.I). Apparently, in addition to the standard nine-books Alexandrian edition of Sappho's lyrics, there was a book of elegies and epigrams widely believed to be by her. [...] The author of the ES surely knew of elegiac poems attributed to Sappho, but was discerning enough to see them as anomalous". ("A tradição biográfica menciona que ela [Safo] também escreveu poesia 
mesma causa para assim a retratar, a saber, a matéria infeliz (infelix) de seu poema. Veja-se na epístola elegíaca das Heroides a alusão a versus flebiles $^{35}$ supostamente compostos pela poetisa Safo por causa de sua infelicidade amorosa (o abandono de Fáon ${ }^{36}$ ), como lemos em: "Talvez questiones os versos alternados" (Heroides, XV, v. 5-6); ${ }^{37}$ em "O meu amor é choroso, a elegia, um verso de lamento" (v. 7); ${ }^{38}$ e em "O pássaro canta Ites, Safo canta amores abandonados" (v. 155). ${ }^{39}$ Como em outras passagens, a carta em que Ovídio empresta a voz a Safo reforça as associações que se têm entre a poesia elegíaca e situações de lamento. ${ }^{40}$

Em Boccaccio, por sua vez, destacamos aqui duas passagens específicas em que se vê semelhante representação de Safo: "[...] assim como Safo se empenhou de modo feliz, do mesmo modo a infeliz padecia de amor" (De mulieribus, XLVII, §4); ${ }^{41}$ e também “[...] dizem que ela cantou versos tristes" ${ }^{\prime 2}$ (LXVII, §4. Cf. ainda BROWN, 2001, p. 195).

Ainda que a certo momento Boccaccio também faça referência a outro tipo de poesia ao qual Safo realmente se dedicara (ao mencionar

elegíaca (Suda s.v. $\Sigma \alpha \pi \varphi \omega ́ ;$ P. Oxy. 1800, fr.I). Aparentemente, além dos nove livros padrão da edição alexandrina da lírica de Safo, havia um livro de elegias e epigramas amplamente creditado a ela [...]. O autor da ES certamente conheceu os poemas elegíacos atribuídos a Safo, mas era suficientemente perspicaz para vê-los como anômalos"; KNOX, 1995, p. 280).

${ }^{35}$ Em relação à escolha do termo flebilis, Knox (1995, p. 281) adverte que em Amores, 3.9.3 (Flebilis indiginos, Elegeia, solue capillos) a personificação da elegia é caracterizada com o mesmo vocábulo que em Tristia, 5.1.5-6 (flebilis ut noster status est, ita flebile Carmen/ materiae scripto conueniente suae; grifos nossos).

${ }^{36}$ Considerado um personagem mítico, Fáon é, segundo podemos observar na décima quinta carta das Heroides, o ex-amante de Safo, por quem ela abandona o amor homossexual.

${ }^{37}[\ldots]$ alterna requiras carmina.

${ }^{38}$ Flendus amor meus est; elegia flebile carmen.

${ }^{39}$ Ales Ityn, Sappho desertos cantat amores.

${ }^{40}$ Cf. Conte (1994), Rimell (2006).

${ }^{41}[\ldots]$ uti feliciter studuit, sic infelici amore capta est.

${ }^{42}[\ldots]$ dicunt versus flebiles cecinisse. 
o verso sáfico), ${ }^{43}$ e também à lira, ${ }^{44}$ a ligação entre tristeza e elegia se apresenta enfatizada em De mulieribus. Exemplos disso são ainda a referência que faz o autor à elegia como o verso mais apropriado ao tema dos poemas tristes de $\mathrm{Safo}^{45}$ e o tom choroso da última frase da biografia, ${ }^{46}$ a qual evoca elementos associáveis à elegia latina. ${ }^{47}$ Evidencia-se, portanto, que a Safo de Boccaccio não é simplesmente a poeta de Lesbos, que escrevera em versos não elegíacos, mas aquela que um poeta elegíaco romano específico, Ovídio, representa. Assim, a imagem de Safo retratada por Boccaccio se constrói com base na imagem observada em Heroides, a qual, por sua vez, aproxima-se do próprio eu poético de Ovídio, uma relação que foi bem apontada por Rimell (2006).

Também a caracterização da poetisa quase como uma divindade pagã é aspecto encontrável tanto na biografia de Boccaccio (segundo parágrafo de XLVII) quanto na décima quinta carta do epistolário ovidiano, como veremos a seguir.

Em De mulieribus, conta-se sobre o banho que Safo teria tomado nas águas da fonte Castália, sua reunião com as musas, a ida até a caverna

\footnotetext{
43 “"....] se não tivesse lido que ela, como que desprezadas as formas dos poemas do passado, inventou um novo gênero, que caminha com pés diferentes dos restantes, e que até hoje é chamado 'sáfico' a partir de seu nome" ([...] ni legissem ab ea, quase preteritorum carminum formis spretis, novum adinvetum genus, diversis a ceteris incendens pedibus, quod adhuc ex eius nomine saphycum appellatur; De mulieribus, XLII, §4).

44 "Tendo tomado o plectro de Febo, a menina não hesitou em tocar as sonoras cordas da cítara e em produzir melodia" (Phebi sumpto plectro, sacris nynphis choream traentibus, sonore cithare fides tangere et expromere modulos puella non dubitavit; De mulieribus, XLVII, §2).

45 "Eu poderia ter pensado que os versos eram elegíacos - já que tais versos são destinados a esse assunto [...]" (Elegos fuisse putassem, cum tali sint elegi attributi materie; De mulieribus, XLVII, §4).

46 "Mas para quê? Parece que as Piérides devem ser acusadas, pois puderam, tocando Anfião a lira, mover as rochas de Tebas; mas, cantando Safo, o coração do jovem não quiseram abrandar" (Sed quid? Accusande videntur Pyerides quem tangente Anphyone lyram, ogygia saxa movisse potuerunt et adolescentis cor, Sapho canente, mollisse noluerunt; De mulieribus, XLVII, §5).

${ }^{47}$ Sabe-se que a elegia não se resume às características que apresenta Ovídio em Heroides, XV, que são os "versos alternados" (v. 5-6, o dístico elegíaco) e o tema de lamento amoroso (v. 7). Cf. Kennedy (1993) para um exemplo de estudo dos topoi elegíacos.
} 
de Apolo, e, ainda, sobre a tomada do plectro de Febo para si mesma. Observemos o texto boccacciano mais de perto:

Na verdade, ainda que ignoremos a época em que ela se teria tornado famosa, foi de tão nobre inteligência que, florescendo em idade e beleza, e não satisfeita em apenas saber escrever, foi impelida por um ardor maior de ânimo e por sua vivacidade do engenho, tendo sido elevada, por sua vigilante dedicação, aos escarpados do Parnaso. No cume altivo, feliz por ter ousado, misturou-se às Musas, que não a rejeitaram, e, percorrido o bosque láureo, chegou até a gruta de Apolo. Tendo bebido a água da fonte Castália, e tomado o plectro de Febo, a menina não hesitou em tocar as sonoras cordas da cítara e em produzir melodia enquanto as sacras ninfas conduziam uma dança. (De mulieribus, XLVII, §2). ${ }^{48}$

Em nosso entender, a apropriação do instrumento pela poetisa descrita por Boccaccio retoma as palavras da personagem Safo da carta ovidiana, passagem em que a poetisa nos fala sobre a adequação da lira a seu caráter e ao deus Apolo-Febo: "Agradecida, eu, Safo, a poetisa, ofereço a ti a lira, Febo: ela convém a mim e a ti" (Heroides, XV, v. 181-184). ${ }^{49}$

Curiosamente, a imagem de poeta atribuída a Safo em Heroides, XV e em De mulieribus, e a associação desta com a divindade Apolo (também nos dois textos), parece não destoar da que o poeta romano constrói para si mesmo em outras obras, como podemos ver nos excertos destacados: "Que a mim o louro Apolo sirva taças cheias de água da

\footnotetext{
${ }^{48}$ Hec etenim, etsi quibus temporibus claruerit ignoremus, adeo generose fuit mentis $u t$, etate florens et forma, non contenta solum literas iungere novisse, ampliori fervore animi et ingenii suasa vivacitate, conscenso studio vigili per abruta Parnasi, vertice celso, se felici ausu, Musis non renuentibus, immiscuit; et laureo pervagato nemore in antrum usque Apollinis evasit et, Castalio proluta latice, Phebi sumpto plectro, sacris nynphis choream traentibus, sonore cithare fides tangere et expromere modulos puella non dubitavit [...].

${ }^{49}$ Grata lyram posui tibi, Phoebe, poetria Sappho;/ Conuenit illa mihi, conuenit illa tibi.
} 


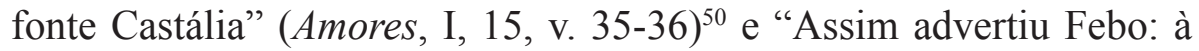
exortação submetei-vos. Na boca sacra deste deus está a segura verdade" (Ars amatoria, II, v. 509-10). ${ }^{51}$ Para Rimell (2006), tal associação entre poetas e deuses não revela um símile meramente decorativo, pois a figura de Apolo representaria, em obras ovidianas como Ars amatoria (II, v. 493) e Amores, o estímulo para a atividade de escrita. ${ }^{52}$

Segundo apontou Sharrock (1994), o próprio Ovídio se apresenta em Amores e Ars amatoria como o "Apolo de sua obra", na medida em que ele é "aquele que tem as chaves da sabedoria, poética e erótica" (p. 218-219). Gostaríamos de sugerir que o retrato de Safo em De mulieribus, XLVII, portanto, pode ser entendido como uma imagem em movimento, uma representação da poetisa na qual se vislumbra não só a personagem de Heroides, XV, mas também, ainda que enviesadamente, a do próprio Ovídio. Dessa forma, a personagem do catálogo boccacciano, assim como a personagem ovidiana, nasce da tensão entre as vozes que remetem ora a elementos - majoritariamente imagéticos - que são representações ovidianas da poesia lírica, ora a elementos - imagéticos e textuais - da própria elegia. Ao mesmo tempo, vimos que a Safo boccacciana retoma a descrição de Safo como poetisa representada em Heroides e, talvez ainda, a autorrepresentação do poeta romano Ovídio associado à caracterização de Apolo. Tal retomada ocorre em parte neste evocar e manipular o imaginário, explícito ou obscuro, das divindades pagãs - explorar tal imaginário nos permite vislumbrar a construção do texto de Boccaccio como ligada ao modus operandi ovidiano.

Se for assim, a presença da Safo ovidiana no De mulieribus é de certa forma coerente com a ideia de que, em Boccaccio, a poesia associar-

\footnotetext{
${ }^{50}$ [...] mihi flavus Apollo/ pocula Castalia plena ministret aqua.

${ }^{51}$ sic monuit Phoebus: Phoebo parete monenti;/ certa dei sacro est huius in ore fides. 52 "Yet for Ovid's audience this is not just a superficial, decorative simile, not least because both Apollo and Bacchus provide the stimulus for writing love poetry at crucial points in Ovid's oeuvre" ("No entanto, para o público de Ovídio, isso não é apenas um símile superficial e decorativo, até porque tanto Apolo quanto Baco fornecem o estímulo para escrever poesia de amor em pontos cruciais na obra de Ovídio"; RIMELL, 2006, p. 144).
} 
se-ia também à teologia. ${ }^{53}$ Assim, percebe-se que uma personagem cuja historicidade é reconhecida por outros autores, acaba, devido a seus dons poéticos, por ser aproximada da esfera divina. No catálogo boccacciano, ocorre, pois, com a biografia de Safo, como que o inverso do que se vê em outras personagens, como Medeia, por exemplo, cujo caráter defendido por Boccaccio como histórico seria um efeito da narrativa e da argumentação em De mulieribus. Safo é, portanto, personagem histórica, mas também divina.

Concluímos, então, assinalando que o diálogo com o texto ovidiano que se observa em passagens da obra De mulieribus não esconde o vetor de moral cristã na leitura boccacciana de Medeia (XVII), e mesmo ressalta a sutil presença desse vetor em Tisbe (XIII). Já no retrato de Safo (XVLII), aspectos morais são aparentemente deixados de lado em favor de um destaque a um retrato de autoria - mas a evocação de um Ovídio apolíneo nos lembra também que tal representação de autor tem muito de divino. Essa figuração da poetisa se baseia em uma representação já construída na literatura: poesia que gera poesia, algo que, ademais, não destoa tanto, no entender de Boccaccio, de uma teologia.

\section{Referências}

ARISTOPHANES. Aristophanes' Lysistrata. Edited with introduction and commentary BY J. Henderson. Oxford: Clarendon Press, 1990.

ARISTOTLE. Poetics. Translated by Stephen Halliwell. Cambridge, Massachusetts, London: Harvard University Press, 1995.

BARCHIESI, A. Otto punti su una mappa dei naufragi. Materiali e discussioni per l'analisi dei testi classici, Pisa, n. 39, p. 209-226, 1997.

\footnotetext{
53 "Dico che la teologia e la poesia quasi una cosa si possono dire, dove uno medesimo sia il suggetto; anzi dico più: che la teologia niuna altra cosa è che una poesia di Dio" (BOCCACCIO. Trattatello in laude di Dante. Fac-símile, sem página. Cf. também a edição de Branca in Boccaccio, 1974). Sobre a relação entre teologia e a poética no período de Boccaccio, a qual também foi muito importante para Mussato (1261-1329), Dante (1265-1321) e Petrarca (1304-1374), cf. Barolini (2013); Ronconi (1976).
} 
BARCHIESI, A. La traccia del modelo: effeti omerici nella narrazione virgiliana. Pisa: Giardini, 1984.

BARCHIESI, A.; HARDIE, P. The Ovidian Career Model: Ovid, Gallus, Apuleius, Boccaccio. In: HARDIE, P.; MOORE, H. (Ed.). Classical Literary Careers and their Reception. Cambridge: Cambridge University Press, 2010. p. 59-88.

BAROLINI, T. La poesia della teologia e la teologia della poesia dalla Rime di Dante al Paradiso. In: PAOLINI, L; PARMEGGIANI, R; VEGLIA, M (a cura di). Il mondo errante: Dante fra letteratura, eresia e storia. Atti del Convegno Internazionale di studio. Bertinoro, 13- 16 settembre 2010. Spoleto: Centro italiano di studi sull'alto medioevo, 2013. p. 537-545.

BESSONE, F. P. Ovidii Nasonis Heroidum epistula XII: Medea Iasoni. Firenze: Le Monnier, 1997.

BLOCH, H. Misoginia medieval. A invenção do amor romântico ocidental. Tradução de Claudia Moraes. Rio de Janeiro: Editora 34, 1995.

BOCCACCIO, G. Boccaccio on Poetry. (Genealogia deorum gentilium, XIV, XV). Translated by Charles G. Osgood. Princeton: Princeton University Press, 1930.

BOCCACCIO, G. Trattatello in laude di Dante. A cura di Vittore Branca. Milano: Arnaldo Mondadori Editore, 1974.

BRANCA, V. (a cura di). Tutte le opere di Giovanni Boccaccio. v. X a cura di Vittorio Zaccaria. 2. ed. Verona: Arnaldo Mondadori Editore, 1967.

BRANCA, V. Giovanni Boccaccio rinnovatore dei generi letterari. In: BALLERINI, C. (a cura di). Atti del Convegno di Nimega sul Boccaccio. Bologna: Pàtron, 1976. p. 13-35.

BROWN, V. Introduction. In: BOCCACCIO, G. Famous Women. Cambridge, MA; London: Harvard University Press, 2001. p. xi-xxi. (The I Tatti Renaissance Library).

CARDOSO, I. T. Introdução à Lisístrata de Aristófanes. In: ARISTÓFANES. Tradução de Ana Maria Pompeu. Lisístrata. São Paulo: Hedra, 2011. p. 9-38. 
CARDOSO, I. T. Metamorfoses no Actéon de Ovídio. In: LEITE, N. V. de A. (Org.). Corpo e linguagem: a estética do desejo. Campinas: Mercado das Letras, 2005. v. 1, p. 45-62.

CARDOSO, I. T. Theatrum mundi: Philologie und Nachahmung. In: SCHWINDT, J. H. (Ed.). Was ist eine philologische Frage?. Frankfurt: Suhrkamp, 2009. p. 82-111.

CAVALlARI, D. N. O Decameron de G. Boccaccio: alguns traços de intertextualidade. Recorte, Três Corações, v. 3, n. 5, p. 4-10, 2006.

CERBO, A. Ideologia e retorica nel Boccaccio latino. Napoli: Ferraro, 1984.

CERBO, A. Metamorfosi del mito classico da Boccaccio a Marino. Pisa: Edizioni ETS, 2001.

CONTE, G. B. Latin Literature: A History. Translated by J. B. Solodow. Londres: John Hopkins University Press, 1994.

CONTE, G. B. The Rhetoric of Imitation: Genre and Poetic Memory in Virgil and Other Latin Poets. Ithaca (NY): Cornell University Press, 1986.

DUBY, G. Idade Média, Idade dos Homens. São Paulo: Companhia das Letras, 1989.

DUBY, G.; PERROT, M (Org.). História das mulheres no Ocidente. Porto: Afrontamento; São Paulo: EBRADIL, 1990.

GARIN, E. Idade Média e Renascimento. Lisboa: Estampa, 1994.

GLARE, P. G. W. (Ed.). Oxford Latin Dictionary (OLD). Oxford: Clarendon Press, 1982.

GRAF, F. Myth in Ovid. In: HARDIE, P. The Cambridge Companion to Ovid. Cambridge: Cambridge University Press, 2002. p. 108-121.

HABINEK, T.; SCHIESARO, A. The Roman Cultural Revolution. Cambridge: Cambridge University Press, 2004.

HILL, D. E. Notes: Book VII. In: OVIDIUS. Metamorphoses: Books V-VII. Edited, with introduction, translation and notes by D. E. Hill. Warminster: Aris \& Phillips, 1992. p. 194-215.

HORTIS, A. Studi sulle opere latine di Giovanni Boccaccio. Trieste, 1879. 
JOCELYN, H. D. Giovanni Boccaccio's interpretations of Graeco-Roman myths and the constraints and impulses of his own times. In: HORN, H.; WALTER, H. (Ed.) Die Allegorese des antiken Mythos. Harrassowitz, 1997. p. 253-265.

JULIANI, T. J. 2016. Vestígios de Ovídio em Sobre as mulheres famosas (De Mulieribus Claris, 1361-1362) de Giovanni Boccaccio. 2016. $220 \mathrm{f}$. Tese (Doutorado em Linguística) - Instituto de Estudos da Linguagem, Universidade Estadual de Campinas, Campinas, 2016.

JULIANI, T. J. Sobre as mulheres famosas (De Mulieribus Claris, 13611362) de Giovanni Boccaccio. 2011. 286 f. Dissertação (Mestrado em Linguística) - Instituto de Estudos da Linguagem, Universidade Estadual de Campinas, Campinas, 2011.

KENNEDY, D. The Arts of Love: Five Studies in the Discourse of Roman Love Elegy. Cambridge: Cambridge University Press, 1993.

KNOX, P. Epistula Sapphus ad Phaonem. In: OVID. Heroides: Select Epistles. Edited and introduced by Peter Knox. Cambridge: Cambridge University Press, 1995. p. 278 - 315.

KOLSKY, S. The Genealogy of Women: Studies in Boccaccio's De Mulieribus Claris. New York: Peter Lang Publishing, 2003.

MAZZOTA, G. Boccaccio: the mythographer of the city. In: WHITMAN, J. (Ed.). Interpretation and Allegory. Antiquity to the Modern Period. Leiden; Boston; Köln: Brill Academic Publishers, 2003. p. 349-364.

MCLEOD, G. Virtue and Venom: Catalogues of Women from Antiquity to the Renaissance. Ann Arbor: University of Michigan Press, 1991.

MORSE, R. The Medieval Medea. Cambridge: D. S. Brewer, 1996.

OVID. Heroides: Select epistles. Edited and introduced by Peter Knox. Cambridge: Cambridge University Press, 1995.

OVIDE. Les Métamorphoses: I-V. Texte établi et traduit par Georges Lafaye. Paris: Les Belles Lettres, 1999.

OVIDE. Les Métamorphoses: VI-X. Paris: Les Belles Lettres, 2000.

OVIDE. L`art d`aimer. Texte établi par Henri Bornecque. Paris: Les Belles Lettres, 1965. 
OVIDE. Heróides. Texte établi par Henri Bornecque. Paris: Les Belles Lettres, 1965.

OVIDE. Les amours. Texte établi e traduit par Henri Bornecque. Paris: Les Belles Lettres, 1924.

OVIDIUS. Metamorphoses: V-VIII. Edited, with introduction, translation and notes by D. E. Hill. Warminster: Aris \& Phillips, 1992.

PETRONE, G. Teatro antico e inganno: finzione plautine. Palermo: Palumbo, 1983.

RIMELL, V. Ovid's Lovers. Desire, Difference and the Poetic Imagination. Cambridge: Cambridge University Press, 2006.

RONCONI, G. LE ORIGINI DELLE DISPUTE UMANISTICHE SULLA POESIA: Mussato e Petrarca. Roma: Bulzoni, 1976.

SHARROCK, A. Seduction and Repetition in Ovid's Ars Amatoria 2. Oxford: Clarendon Press, 1994.

TORRETTA, L. Il liber De Claris Mulieribus di Giovanni Boccaccio. Giornale storico della letteratura italiana, Torino, v. 39, p. 252-292, 1902.

TREVIZAM, M. A elegia erótica romana e a tradição didascália como matrizes compositivas da Ars Amatoria de Ovídio. 2003. 271 f. Dissertação (Mestrado em Linguística) - Instituto de Estudos da Linguagem, Universidade Estadual de Campinas, Campinas, 2003.

VASCONCELLOS, P. S. Persona poética e autor empírico na poesia amorosa romana. São Paulo: UNIFESP, 2016.

ZACCARIA, V. Introduzione. In: BRANCA, V. (a cura di). Tutte le opere di Giovanni Boccaccio. vol. X a cura di Vittorio Zaccaria. 2. ed. Verona: Arnaldo Mondadori editore 1967. p. 3-16.

Recebido em: 29 de abril de 2018. Aprovado em: 15 de junho de 2018. 